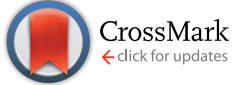

Cite this: RSC Adv., 2016, 6, 13846

\section{Investigation on electromagnetic characteristics, microwave absorption, thermal and mechanical properties of ferromagnetic cobalt-polystyrene composites in the X-band (8.4-12.4 GHz)}

\begin{abstract}
Azizurrahaman Ansari*a and Mohammad Jaleel Akhtar ${ }^{\text {ab }}$
The electromagnetic, thermal and mechanical properties of ferromagnetic cobalt-polystyrene composites in the X-band (8.4-12.4 GHz) are investigated in order to explore their usage for wide band microwave absorbers. The cobalt-polystyrene composites are prepared by mechanical blending method using automated injection molding equipment. The microwave absorption properties of cobalt-polystyrene (Co-PS) composites with different cobalt weight ratios are investigated in order to determine the optimum weight ratio for design of efficient microwave absorbers. In order to understand the electromagnetic absorption process at micro level, the X-ray diffraction (XRD) and scanning electron microscopy (SEM) of various samples are carried out to obtain information about the existence and dispersion of Co filler in the Co-PS composite samples, respectively. The thermal stability of the synthesized Co-PS composites is analyzed using the thermo gravimetric analysis (TGA), while the surface hardness is measured using Shore D hardness tool. The tensile and flexural tests are performed to find out the mechanical properties of the molded composites. The complex permittivity $(\varepsilon)$ and permeability $(\mu)$ of the Co-PS composites are extracted from the scattering data obtained using the vector network analyzer (VNA) measurements in the X-band of microwave frequency. The reflection losses (RL) in the composites are calculated using the complex permittivity and permeability parameters. The minimum reflection loss (maximum absorption) of $-19.85 \mathrm{~dB}(98.96 \%)$ at $10.22 \mathrm{GHz}$ is achieved for $30 \mathrm{wt} \%$ Co-PS composite with thickness of $5 \mathrm{~mm}$, and this value reaches to $-31.6 \mathrm{~dB}(99.93 \%)$ at 9.04 $\mathrm{GHz}$ with thickness of $10 \mathrm{~mm}$. For $5 \mathrm{wt} \%$ Co-PS composite, the minimum reflection loss of $-4.90 \mathrm{~dB}$ (67.66\%) at $10.72 \mathrm{GHz}$ is achieved with thickness of $5 \mathrm{~mm}$. The experimental results reveal that the microwave absorption properties of the synthesized composites in the X-band can be improved by changing the ferromagnetic cobalt weight ratios in the composite.
\end{abstract}

Received 11th December 2015 Accepted 22nd January 2016

DOI: $10.1039 / \mathrm{c} 5 \mathrm{ra} 26489 \mathrm{~h}$

www.rsc.org/advances the stealth technology which involves design of special kinds of materials to be used as microwave absorbers in order to minimize the visibility of the target. $^{6-11}$ An ideal microwave absorbing material should possess strong absorption capability, wide bandwidth, light weight, mechanically strong, good thermal and oxidation stability. ${ }^{12}$ The ferromagnetic transition metals are the most conventional EM absorbing materials due to their high Snoek limit, sufficient skin depth and reduced eddy current losses. ${ }^{\mathbf{1 2 - 1 4}}$ However, the application of ferromagnetic transition metals is greatly limited due to its high agglomeration capability and oxidation effect. In order to minimize these effects, the ferromagnetic transition metals are either coated with oxide materials, ${ }^{\mathbf{1 1 5}, \mathbf{1 6}}$ or dispersed in the polymer matrix. ${ }^{17-19}$ L. Yan et al. measured the microwave absorption (99\%) of $\mathrm{SiO}_{2}$ nanoshell coated iron nanoflakes in the frequency range of 1-18 GHz, and Zhang et al. measured the microwave absorption (99.5\%) of iron nanoparticles embedded in $\mathrm{Al}_{2} \mathrm{O}_{3}$ matrix in 1-18 GHz. ${ }^{15,16}$ However, the oxide coated
${ }^{a}$ Materials Science Programme, Indian Institute of Technology Kanpur, Kanpur 208016, India.E-mail: aziz@iitk.ac.in

${ }^{b}$ Department of Electrical Engineering, Indian Institute of Technology Kanpur, Kanpur 208016, India 
composites are restricted in their practical applications due to relatively narrow absorbing frequency range and high coating density. In recent years, several research groups have been working with ferrites as efficient magnetic fillers for preparing magnetic microwave absorber. ${ }^{\mathbf{2 0 - 2 4}}$ The preparation of ferrite is easy when compared with the preparation of metals and metal alloys. However, one of the challenges with ferrites is their low microwave absorption bandwidth and high density. Hence, there is a lot of interest nowadays to use the ferromagnetic metals (Fe, Co, and Ni) and their alloys in lieu of ferrites for effective wide band microwave absorption. ${ }^{17-19}$ In order to achieve wide absorbing frequency range, light weight, strong thermal and chemical stability, and peerless microwave absorption performance, the composites with magnetic metal dispersed in polymer matrix are preferred. It is mainly due to this reason that a number of research groups in the recent past have used this methodology to prepare microwave absorbers. For example, Kim et al. have dispersed iron particles into rubber matrix to prepare the composite, and the measured reflection loss of $-5 \mathrm{~dB}$ (70\% absorption) has been reported in 1-2 GHz frequency range. ${ }^{17}$ Similarly, M. Matsumoto's group prepared polymer composite containing carbonyl iron and studied the microwave absorption in the quasi-microwave band. ${ }^{18}$ Akman et al. coated $\mathrm{Ni}$ and Co with polyacrylonitrile, and found their enhanced microwave absorption ( 99.99\%). ${ }^{19} \mathrm{H}$. Wang et al. prepared $30 \mathrm{wt} \% \mathrm{Co} /$ polypyrrole nanocomposite and measured microwave absorbing properties in 1-18 GHz. ${ }^{25}$ They found 99.95\% (-33 dB) microwave absorption at $13.6 \mathrm{GHz}$ (Ku band). The disadvantage is that Co/polypyrrole composite is not suitable for room temperature and high temperature solid state applications because of its liquid nature (b.p. of polypyrrole $\sim 130{ }^{\circ} \mathrm{C}$ ).

In the present work, different contents of cobalt fillers are dispersed in the polystyrene matrix to synthesize Co-PS composites, and the complex permittivity and permeability of the resultant composite are measured in the microwave frequency range of 8.2-12.4 GHz to explore its usage as efficient microwave absorber. It is to be noted that the Co-PS composite can work over a wide temperature range starting from the room temperature due to its good mechanical and thermal stability. The Co micro particles are chosen as magnetic components due to their excellent ferromagnetic properties, e.g. strong exchange force, controllable crystal structure, and tunable magnetic properties. $^{25-27}$ The polystyrene (PS) has been chosen as the matrix due to its good thermal properties (m.p. $\sim 240{ }^{\circ} \mathrm{C}, T_{\mathrm{g}} \sim$ $100{ }^{\circ} \mathrm{C}$ ), controllable dielectric constant and reasonably light weight. ${ }^{28}$ Also, PS is widely used in several applications because of its heat durability, nontoxicity, mechanically strength, and thermally non degradable properties. In order to investigate the microwave absorbing properties of the composite samples in the X-band of microwave frequency, the reflection losses in the samples are evaluated. The structural, morphological, mechanical and thermal properties of the synthesized composite samples are also studied in order to ensure that the resultant material is thermally and mechanically stable.

The main aim of our paper is to explore the usage of the CoPS composites as thermally non degradable, mechanically stable, and efficient microwave absorbers for the X-band of microwave frequency. In this work, a maximum of $30 \mathrm{wt} \%$ of Co in the PS-matrix is added in order to synthesize light weight, effective microwave absorbers without compromising much on the absorption bandwidth. The present study is useful to design microwave absorbers for radio detection and ranging (RADAR) applications, because most of the RADAR applications work in the X-band of microwave frequency. In addition, various high frequency electronic devices such as weather monitoring device, air traffic/maritime vessel traffic control devices, speed detection device, and some electron paramagnetic resonance (EPR) spectrometer, etc. are also being operated in X-band of microwave frequency. For all these applications, the present study of $\mathrm{X}$-band microwave absorber with higher filler content of Co-PS composite would be quite helpful in order to design EMI/EMC compatible devices. To the best of author's knowledge, this kind of detailed study regarding the preparation and characterization of Co-PS composites in terms of their mechanical, physical, thermal, and microwave absorption properties in the $\mathrm{X}$-band of microwave frequency has not been done in the past.

\section{Experimental}

\subsection{Sample preparation}

The automated injection moulding (Xplore $\AA$ ) is used for the preparation of cobalt-polystyrene composite sheets, which provides good dispersive and distributive mixing of cobalt particles in the base matrix of the polystyrene. The cobalt powder $(<150 \mu \mathrm{m}, 99.9 \%)$ and high impact polystyrene granules (SH3001) were purchased from Sigma Aldrich and Supreme Petrochem Limited, respectively. These raw materials are fed into the mixer using hoper. The mixing of cobalt and PS is performed for $3 \mathrm{~min}$ in Xplore ${ }^{\circledR}$ MC 5 micro compounder at the chamber temperature of $220^{\circ} \mathrm{C}$. During the mixing process, the speed of twin screw is programmed at $50 \mathrm{rpm}$ for the suitability of the micro compounder. For obtaining the proper shape of the test specimen, the composite mixture of cobalt and PS is fed to the Xplore ${ }^{\circledR}$ IM 5.5 micro injection moulder, where the temperature of moulder and barrel are maintained $50{ }^{\circ} \mathrm{C}$ and $230{ }^{\circ} \mathrm{C}$, respectively. The pressure (feeding zone $-5 \mathrm{bar} / 2 \mathrm{~s}$, holding zone $-8 \mathrm{bar} / 10 \mathrm{~s}$, and releasing zone $-8 \mathrm{bar} / 2 \mathrm{~s}$ ) is applied to the piston to move the molten composite mixture from barrel to moulder, which results into formation of the composite sheet with approximate thickness of $5 \mathrm{~mm}$.

\subsection{Characterization techniques}

X-ray diffraction (XRD) patterns of cobalt powder and Co-PS composite samples are recorded in an X-ray diffractometer (PANalytical X'Pert) in $2 \theta$ range of $30-70^{\circ}$ with $\mathrm{Cu} \mathrm{K}_{\alpha}$ radiation (wavelength $=1.540562 \AA$ ), scan rate of $2^{\circ}$ per min, step size of $0.05^{\circ}$ and time constant of $1 \mathrm{~s}$. The samples are analyzed for the identification of Co particles on the surface of Co-PS composite sheets.

The scanning electron microscopy (SEM) and the energy dispersive spectroscopy (EDS) of the samples are performed using the scanning electron microscope (model: JSM-6010LA, 
JEOL). The aim of SEM microphotography is to observe the dispersion of Co particles into the PS base matrix.

The thermogravimetric analysis (TGA) technique is carried out to analyze the effect of cobalt doping on the thermal stability of Co-PS composites. The actual measurement is performed using a thermogravimetric analyzer (model: TGA 4000, PerkinElmer) in air atmosphere in a programmed temperature range from 35 to $600{ }^{\circ} \mathrm{C}$ at a heating rate of $5{ }^{\circ} \mathrm{C} \mathrm{min}^{-1}$.

The Shore D hardness of the prepared composite samples is measured using a digital shore D type durometer hardness tester (range: 0-100 HD, resolution: $0.5 \mathrm{HD}$ ) in order to analyze the surface hardness mechanical property of Co-PS composites.

The tensile and the flexural tests have been carried out using universal testing machine "Zwick/Roell, model: Z010, max. test load: $10 \mathrm{kN}$, max. crosshead speed: $1000 \mathrm{~mm} \mathrm{~min}^{-1}$, crosshead travel resolution: 0.095, max. power consumption: $0.8 \mathrm{kVA}$ ". For the tensile and flexural measurements, the crosshead speed of $50 \mathrm{~mm} \mathrm{~min}^{-1}$ has been fixed. Three point loading method is adopted for flexural test. Three tensile and flexural tests are performed for each sample and averaged them to find out the result.

To study the microwave absorption properties of the prepared composites in the X-band, the samples of the prepared composite sheets are precisely machined so as to fit precisely inside the cross-section of the X-band rectangular waveguide $(22.86 \mathrm{~mm} \times 10.16 \mathrm{~mm})$. The reflection and transmission coefficients of these samples are then measured in the X-band using the network analyzer (Agilent E8364B PNA series). Finally, the complex permittivity and permeability of the composite samples are extracted in the frequency range of 8.412.4 $\mathrm{GHz}$ in terms of the measured scattering data using the reflection-transmission approach. ${ }^{29,30}$

\section{Electromagnetic characteristics and microwave absorption theory}

The microwave absorbers are mainly characterized by their electromagnetic properties in terms of the complex permittivity and the complex permeability. The complex permittivity and the complex permeability are the inherent macro properties of materials that measure the material's interaction with the electric field and the magnetic field, respectively. The complex permittivity arises from the dielectric polarization of the materials and is defined as ${ }^{31}$

$$
\varepsilon_{\mathrm{r}}=\varepsilon^{\prime}-j \varepsilon^{\prime \prime}
$$

where $\varepsilon^{\prime}$ is the real part of the complex permittivity (also known as the dielectric constant), and $\varepsilon^{\prime \prime}$ is the imaginary part of the complex permittivity. The real and the imaginary parts of the complex permittivity are mainly associated with the stored energy and the energy dissipation of the materials, respectively.

The dielectric loss tangent of the material is defined as

$$
\tan \delta_{\mathrm{e}}=\frac{\varepsilon^{\prime \prime}}{\varepsilon^{\prime}}
$$

Analogous to the complex permittivity, the complex permeability is written as ${ }^{31}$

$$
\mu_{\mathrm{r}}=\mu^{\prime}-j \mu^{\prime \prime}
$$

where $\mu^{\prime}$ and $\mu^{\prime \prime}$ represent the real and imaginary parts of the complex permeability of the materials, respectively.

The magnetic loss tangent of the material is defined as

$$
\tan \delta_{\mathrm{m}}=\frac{\mu^{\prime \prime}}{\mu^{\prime}}
$$

In this work, the measurements of complex permittivity and permeability of the composite samples are carried out in the frequency range of 8.4-12.4 GHz. The measured complex permittivity and permeability data of composite samples along with the thickness are used to calculate the reflection loss of the composites. For a metal-backed single layer absorber, the reflection loss $(R)$ is expressed as $^{31,32}$

$$
\begin{gathered}
R(\mathrm{~dB})=20 \log _{10}\left|\frac{Z_{\text {in }}-1}{Z_{\text {in }}+1}\right| \\
Z_{\text {in }}=\sqrt{\frac{\mu_{\mathrm{r}}}{\varepsilon_{\mathrm{r}}}} \tanh \left[j\left(\frac{2 \pi f d}{c}\right) \sqrt{\mu_{\mathrm{r}} \varepsilon_{\mathrm{r}}}\right]
\end{gathered}
$$

where, $Z_{\text {in }}$ is the normalized input impedance with reference to free space, $f$ is the frequency of operation, $d$ is the thickness of the absorber sheet, and $c$ is the velocity of light in free space. For a perfect absorber, $Z_{\text {in }}=1$, which is called the impedance matching condition.

\section{Results and discussions}

\subsection{X-ray diffraction analysis}

The X-ray diffraction patterns of cobalt (Co), polystyrene (PS) and cobalt-polystyrene composites (5-30 wt\% Co) are shown in Fig. 1. In the XRD pattern of pure cobalt, the peak intensities are obtained at angle $2 \theta=41.78^{\circ}, 44.37^{\circ}, 47.26^{\circ}$ and $51.28^{\circ}$, which are exactly matched with the ICSD reference pattern code; 00001-1259 of cobalt with corresponding reflection planes (100), (111), (101), and (200), respectively. ${ }^{33}$ The pure cobalt, which

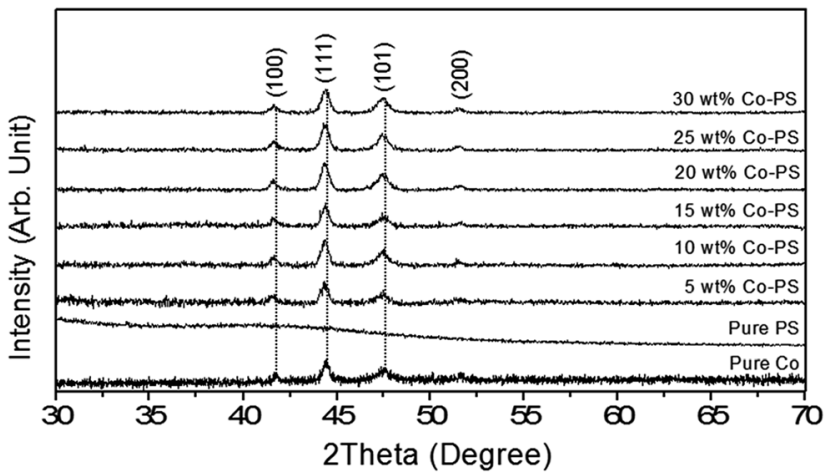

Fig. 1 X-ray diffraction patterns of pure Co, PS and 5-30 wt\% Co-PS composites. 
was obtained by the reduction of $\mathrm{CoO}$ in the presence of $\mathrm{H}_{2}$ at $600{ }^{\circ} \mathrm{C}$, corresponds to the perfect cubic close-packed lattice $(\beta-$ Co, FCC lattice) $)^{33}$ with lattice parameter $3.554 \AA$. The XRD pattern of the pure polystyrene shows the amorphous structure of the polystyrene and no Bragg peak corresponding to crystalline phase has been detected. In the XRD pattern of the polystyrene composites with different loading of cobalt filler (5$30 \mathrm{wt} \% \mathrm{Co}$ ), the Bragg's peaks similar to the cobalt are detected, which are assigned to the presence of cobalt. Furthermore, when adding the cobalt filler into polystyrene matrix, the Bragg's peaks of cobalt are little bit shifted towards the lower value of $2 \theta$. This small shift of peaks of the cobalt-polystyrene composites clearly shows that the embedding of cobalt particles into polystyrene matrix influences the microstructure of composites by means of interfacial interaction between the cobalt particles and polystyrene matrix. ${ }^{34}$

\subsection{Scanning electron microscopy analysis}

Fig. 2 shows the scanning electron microscopy images of the prepared samples. The SEM microphotograph of the thermally prepared cobalt powder used as the filler material in the polymeric composites is shown in Fig. 2a, which reveals an agglomerated particle morphology in dendrite and rod shape. This particle morphology is in accordance with the results reported earlier. ${ }^{35,36}$ The SEM image of the cross sectional polystyrene sheet is shown in the Fig. $2 b$, which exhibits a smooth surface morphology. Fig. 2c-e reveal the SEM images of the cross sectional Co-PS composite sheets with 10, 20, and $30 \mathrm{wt} \%$ cobalt filler content, respectively. The Co as well as PS materials

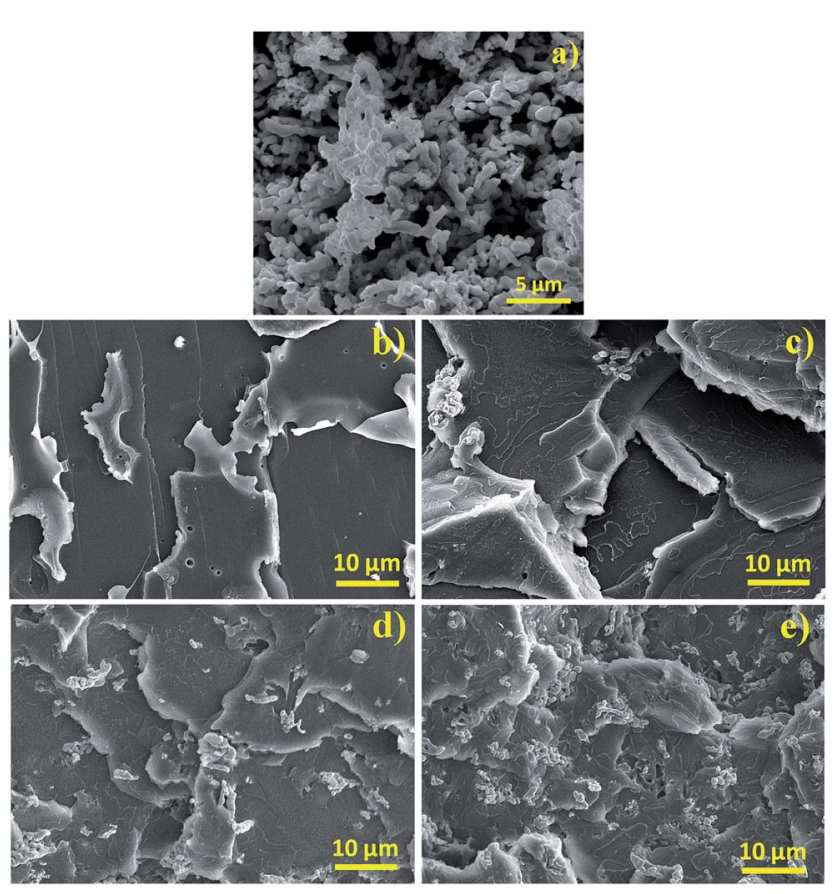

Fig. 2 Scanning electron microscopy images of the samples, (a) pure cobalt powder, and the cross sectional views of the sheets, (b) pure polystyrene, (c) 10 wt\% Co-PS, (d) 20 wt\% Co-PS, and (e) 30 wt\% CoPS composites. have clearly been identified with the help of energy dispersive spectroscopy (EDS) analysis, which is shown in Fig. 3. This EDS shows that no other impurities have been found in the composite samples. It is to be noted that for all the prepared Co-PS composites, the agglomerated Co particles are dispersed into the PS matrix and are well adhered with the matrix material. According to the SEM analysis, the cobalt-polystyrene interface area is increasing with the addition of cobalt content, which will definitely increase the interfacial polarization within Co-PS composites.

\subsection{Thermo gravimetry analysis}

In order to study the thermal stability of the mechanically blended samples of polystyrene (PS) and polystyrene composites with cobalt filler, its weight is monitored by raising the temperature at the rate of $5{ }^{\circ} \mathrm{C} \mathrm{min}{ }^{-1}$ in air environment up to $600{ }^{\circ}$ C. Fig. 4 shows the thermogravimetric analysis (TGA) and differential thermogravimetric analysis (DTA) results of $\mathrm{Co} / \mathrm{PS}$ composites, which provides an indication regarding to the amount of weight lost during the decomposition process of $\mathrm{Co} /$ PS composites. The TGA/DTA curves are mainly divided into three major parts; stage-I, stage-II and stage-III. The first part of the TGA/DTA curve (stage-I) that commonly ranges from $35^{\circ} \mathrm{C}$
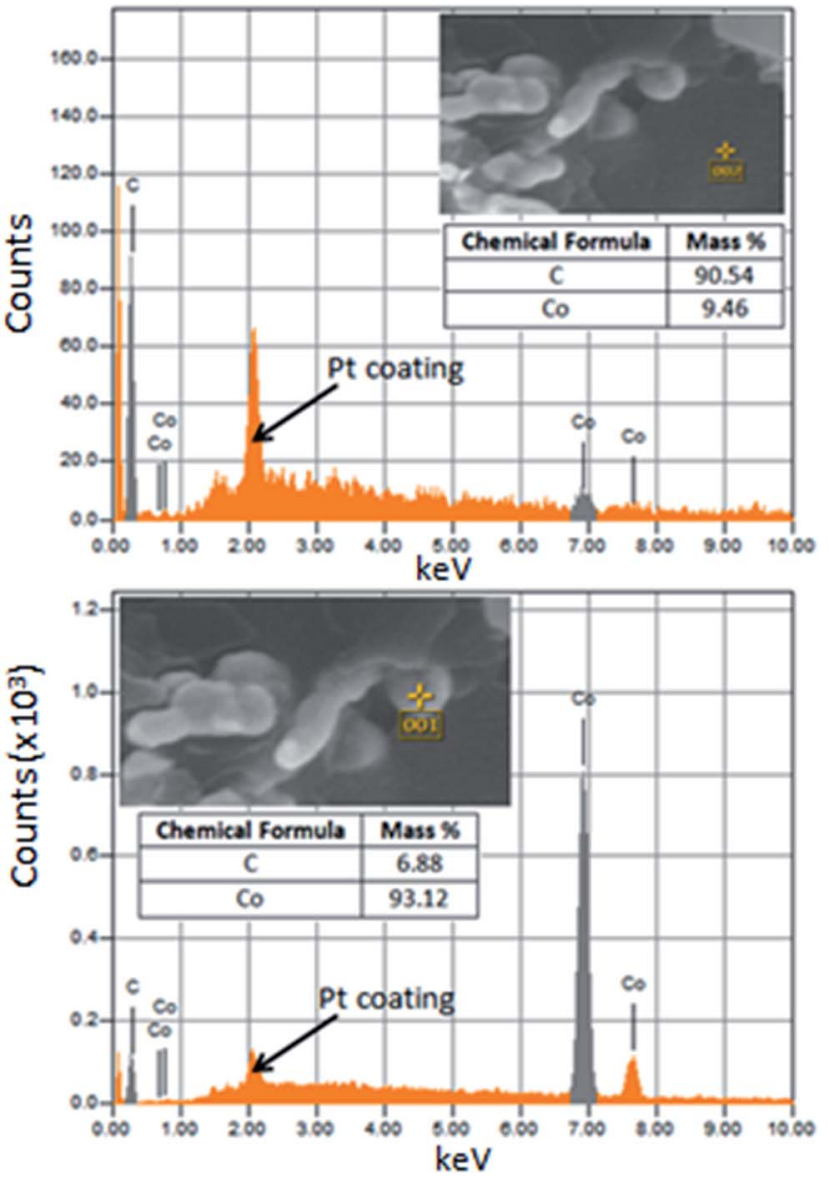

Fig. 3 Energy dispersive spectroscopy (EDS) of 10 wt\% Co-PS composite. 


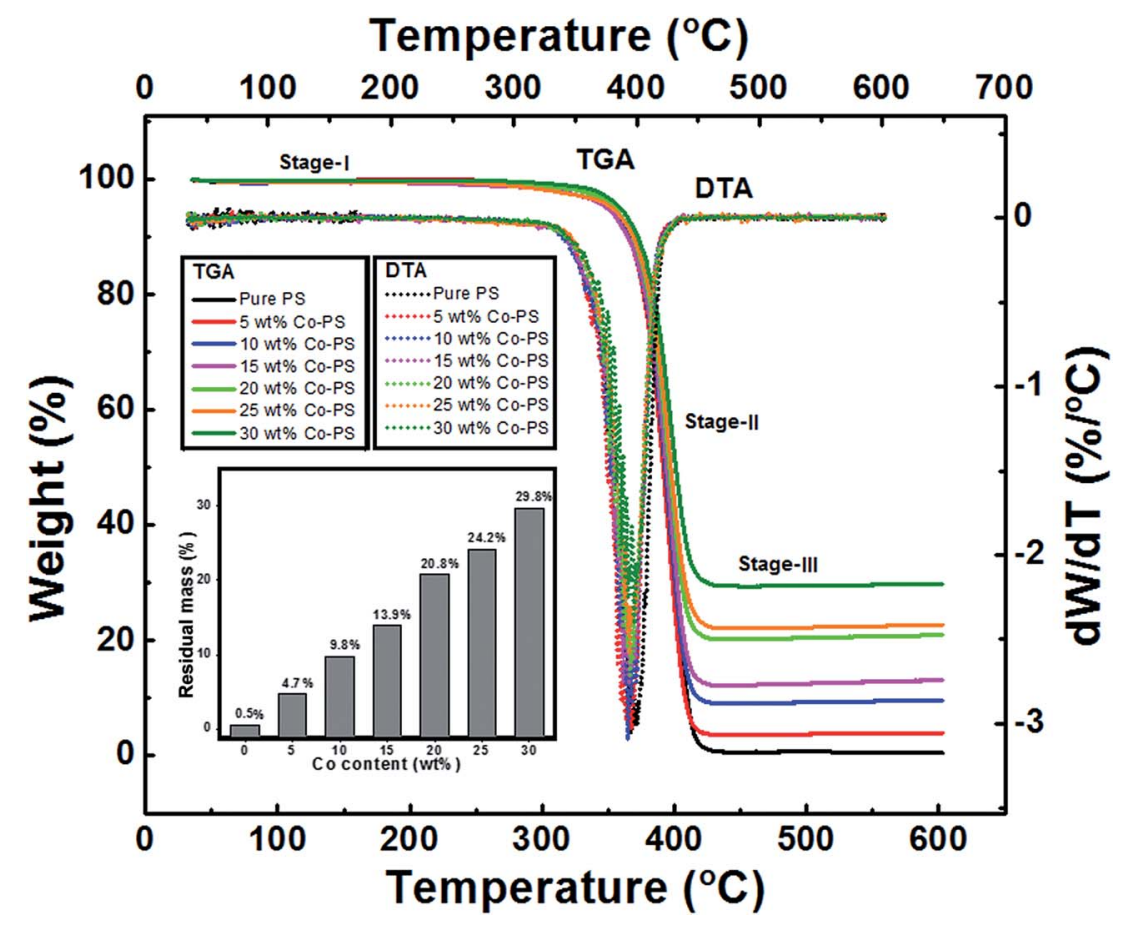

Fig. 4 TGA/DTA curves for pure polystyrene and 5-30 wt\% Co-PS composites. Inset for residual mass (\%) for each case.

to $300{ }^{\circ} \mathrm{C}$ for the samples, is attributed to the moisture vaporization adsorbed on to the surface of the polystyrene molecules. In this part, the weight loss is very less for PS and PS based composite samples. This analysis shows that the environmental humidity does not affect the properties of PS and PS based composites.

The main part (stage-II) in TGA/DTA curve is the thermal decomposition of PS and Co/PS composites in the temperature range of $300-440{ }^{\circ} \mathrm{C}$, where the maximum weight loss occurs. The maximum weight loss in this thermal decomposition process (stage-II) may be attributed to the main chain pyrolysis $^{37,38}$ and the evolution of aromatics from the degradation of the styrene. The onset temperature ( $T_{\text {onset }}$ mean with std. error), which depicts the beginning of the thermal decomposition of the polymer and polymer based composites, is plotted as function of cobalt content as shown in Fig. 5. The onset temperature $T_{\text {onset }}$ (mean) linearly increases with the increase of cobalt content, which shows the strong adherence between the cobalt particles and polystyrene matrix at the interface resulting into suppression of the mobility of the polymer segments near the interface. ${ }^{38}$ This analysis reveals that the thermal stability of composites increases on increasing of the cobalt content. The improvement in the thermal stability of composites by increasing the cobalt filler content can be attributed to partially altering the molecular mobility of the polymer chains due to their adsorption on the surface of the filler particles. ${ }^{39}$ From Fig. 5, a sudden increase in the decomposition peak temperature ( $T_{\mathrm{o}}$ mean with std. error) can be observed if one moves from PS to the PS based composite samples. This decomposition peak temperature $T_{\mathrm{o}}$ (mean) is nearly similar for all the composite samples. The abrupt enhancement in the decomposition peak temperature $T_{\mathrm{o}}$ (mean) may be attributed to the barrier effect by filler particles, where the filler particles help to slow down the volatilization during the thermal decomposition of the polymer. The occurrence in lowering of the volatilization process assists composites with high thermal stability. This can also occur due to the adsorption of polymer chains onto the surface of filler particles, which restricts the segmental mobility and serves to suppress the redistribution and chain transfer reactions..$^{39,40}$

The third part (stage-III) in the TGA/DTA curve shows the residue of the samples at the end of the experiment, which is shown in Fig. 4 (inset). It is observed from the residual mass

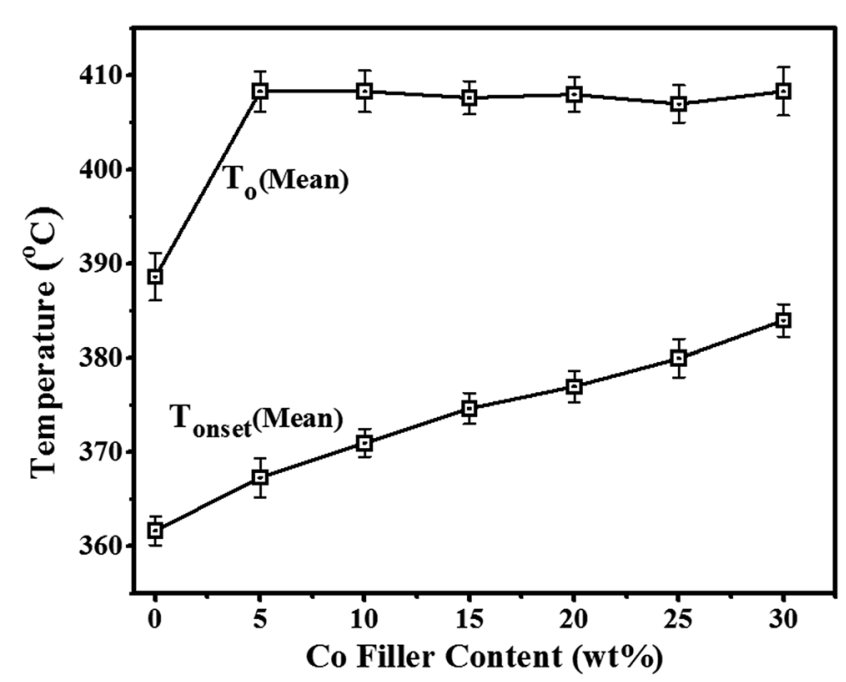

Fig. 5 Plot for onset temperature ( $T_{\text {onset }}$ mean with standard error) and oxidation temperature ( $T_{\circ}$ mean with standard error) with ferromagnetic Co weight ratio. 
results of the samples that polystyrene is almost fully decomposed (residual mass $\sim 0.5 \%$ ) during thermal decomposition (stage-II), and for the composites the residual mass is due to cobalt content only used during the preparation of the composites.

\subsection{Shore D hardness test}

In order to measure the surface resistance of the Co-PS composites to scratching or indentation, the Shore hardness test has been carried out. Fig. 6 shows the hardness (Shore D) results of Co-PS composite sheets as a function of cobalt content. The hardness of the Co-PS composites is increasing with the addition of cobalt filler content, which is in accordance with the reported result. ${ }^{41}$ The increased hardness value of the composites is attributed to the cobalt filler content, strong interaction between Co and PS, and dispersion of the Co into the PS matrix. The strong interconnection and interconnectivity between the reinforcing constituents have been originated from the pressure applied during the preparation of sheets by injection molding. ${ }^{41}$ Thus the surface resistance of the composite to the scratching can be enhanced by incorporation of the particulate cobalt as filler into the polystyrene matrix.

\subsection{Tensile and flexural tests}

4.5.1 Tensile analysis. Fig. 7a represents the typical tensile stress-strain curves of the polystyrene and cobalt doped polystyrene composites. Three tensile tests are performed for each type of sample and the results from the multiple tests are averaged out for each sample. The effect of cobalt filler content on the ultimate tensile strength (UTS mean) of the composites and the percentage increase in tensile strength is shown in Fig. 7b. It is obvious from the Fig. $7 \mathrm{a}$ and $\mathrm{b}$ that the obtained tensile strength of the composites increases with the increase in the cobalt filler contents. The results obtained from the tensile test are in accordance with the earlier reported results. ${ }^{\mathbf{4 2 , 4 3}}$ The

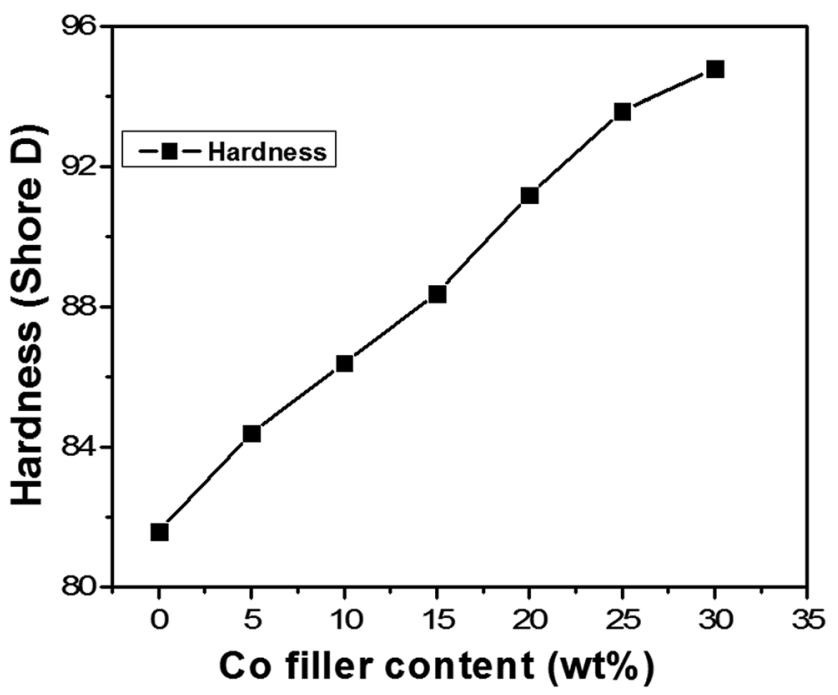

Fig. 6 Hardness (Shore D) result of Co-PS composite with the cobalt filler content.
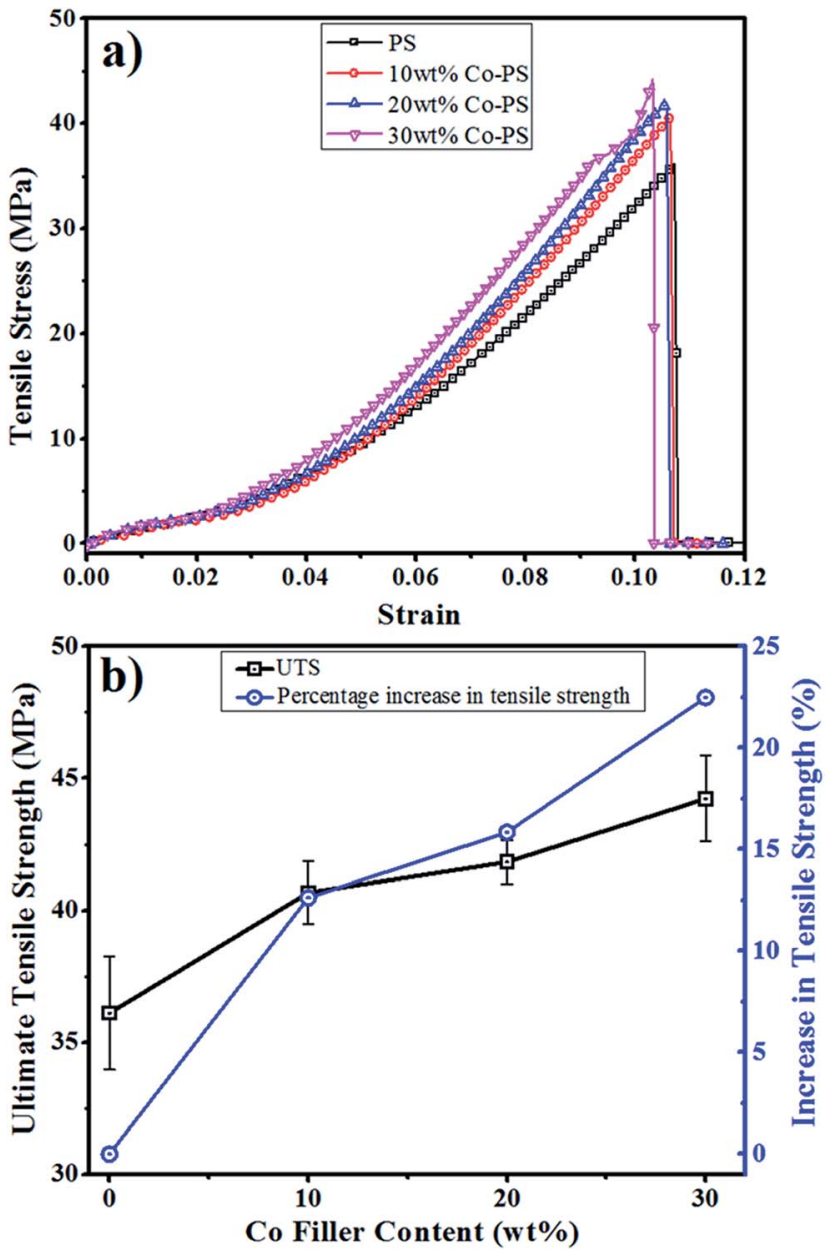

Fig. 7 (a) Typical tensile stress-strain plots of the PS and Co-PS composites, (b) effect of cobalt concentration on UTS (mean) and tensile strength of Co-PS composites. * Note: 3 tensile tests performed for each type of samples, and the values shown are their means.

enhancement in the tensile strength of the Co-PS composites is probably due to the well dispersion quality of the cobalt filler in the PS matrix and the good interfacial bonding between the cobalt particles and the PS matrix. Additionally, the process conditions used in the synthesis of the Co-PS composite sheets play an important role to improve the mechanical properties of the composites. ${ }^{42,43}$

4.5.2 Flexural analysis. The flexural test has been performed by the three point loading method. The flexural stress and the flexural strain are calculated using sets of equations given below. ${ }^{44}$ The flexural stress is defined as:

$$
S=\frac{3 P L}{2 b d^{2}}
$$

where $S, P, L, b$ and $d$ denote the flexural stress, the maximum load, the span length, the width and the thickness of the sample used, respectively. Similarly, the flexural strain is defined as:

$$
r=\frac{6 D d}{L^{2}}
$$


where $D$ is the deflection. The flexural stress-strain curves of the polystyrene and Co-PS composites are shown in Fig. 8a. These flexural stress and flexural strain values are calculated using eqn (7) and (8), respectively for each sample. It is to be noted that each sample is subjected to flexural test thrice, and the average value is plotted in the graph. The variations in the maximum flexural strength (MFS mean) of the Co-PS composites with different cobalt concentrations are revealed in Fig. 8b. It is to be noted that the addition of different cobalt content in the PS matrix enhances the flexural strength of the composites. However, during the flexural measurement of $20 \mathrm{wt} \% \mathrm{Co}-\mathrm{PS}$ and $30 \mathrm{wt} \%$ Co-PS composites, the slipping of the sample holder were observed, which may be the reason to get some fluctuation in these samples at higher compressive forces. It can be seen that the flexural strength values are higher than the corresponding tensile strength values. The difference in flexural and tensile strengths is attributed to the nature of tests involved. The tensile test involves only tension while flexural involves both the tension as well as the compression. In the flexural measurement, the upper half of the composite sheet undergoes compression and the lower half of the composite
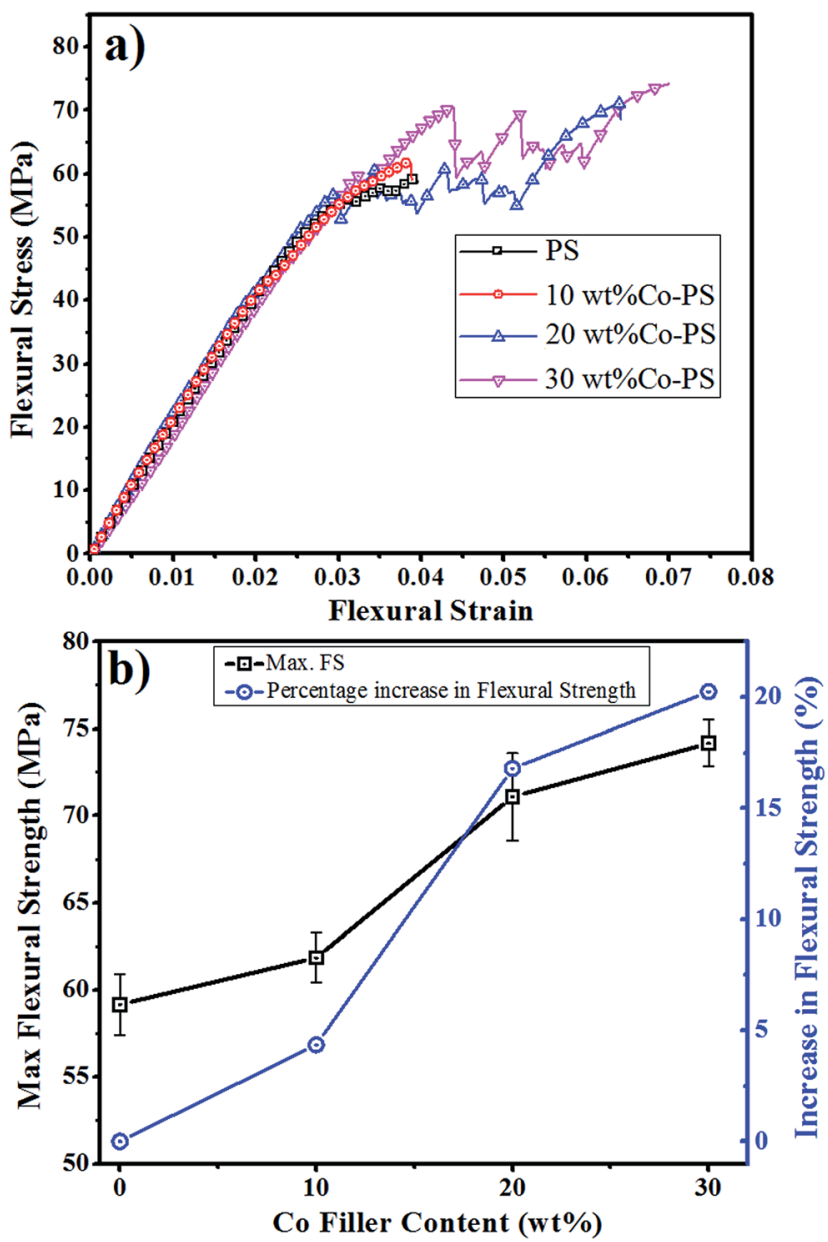

Fig. 8 (a) Flexural stress-strain plots of the PS and Co-PS composites, (b) effect of cobalt concentration on MFS and flexural strength of $\mathrm{Co}-$ PS composites. * Note: 3 tensile tests performed for each type of sample, and the values shown are their means. sheet experiences tension due to the bending of the sheet. Therefore, the crack propagation along compressive side is slow and the compression helps to close the cracks rather than opening them. This phenomenon leads to ductile nature and higher flexural strength. ${ }^{42}$

\subsection{Electromagnetic parameters and microwave absorption}

Fig. 9a shows the real part of the complex permittivity values of cobalt-polystyrene composite samples in the X-band of microwave frequency. It is obvious from this figure that all the samples show almost constant $\varepsilon^{\prime}$ values throughout the whole $\mathrm{X}$-band frequency range for a particular value of filler content. This kind of behavior is observed for most of the plastics where the dielectric properties are mostly constant over a wide frequency band. It is, however, to be noted that the real part of the complex permittivity of composite samples starts increasing significantly when the ratio of cobalt filler into the polystyrene matrix increases beyond a limit $(15 \mathrm{wt} \% \mathrm{Co})$. The increase of
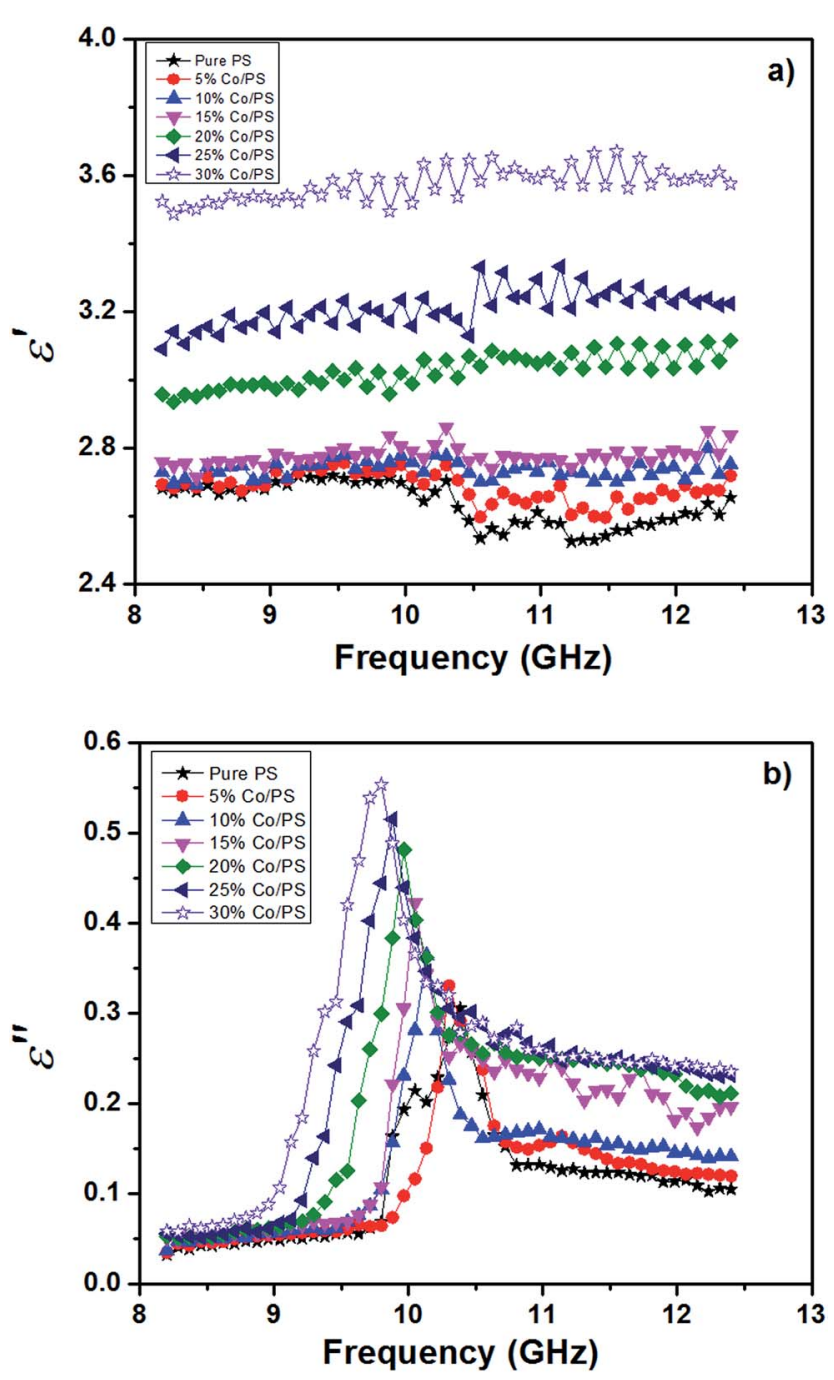

Fig. 9 The complex permittivity of Co-PS composites $(0-30$ wt\% Co filler) in the X-band of microwave frequency, (a) real part of complex permittivity, (b) imaginary part of complex permittivity. 
real part of the complex permittivity with the increase of cobalt loading at any particular frequency is in accordance with the other reported results, ${ }^{45-48}$ and can be understood by the interfacial polarization mechanism in which an increase of the polystyrene/cobalt interface area and charge values separating at interfaces occurs on increasing the cobalt content. This results into a local increase of the electric field which then leads to the enhancement of the real part of the complex permittivity. ${ }^{49,50}$

Fig. 9b shows the imaginary part of the complex permittivity of cobalt loaded polystyrene composite samples in the X-band. This dielectric loss factor is getting increased by the addition of cobalt content over the whole frequency range of X-band as can be clearly observed in Fig. 9b. This obtained pattern is in accordance with other results reported in the past. ${ }^{51,52}$ If one looks at each curve individually, then it can be observed that the loss factor increases and attains the maximum (peak) value at a particular frequency, and then starts decreasing up to upper limiting frequency $(12.4 \mathrm{GHz})$ of X-band. For instance, the maximum of loss factors (imaginary part of the complex permittivity) are 0.31 at $10.38 \mathrm{GHz}, 0.33$ at $10.3 \mathrm{GHz}, 0.37$ at $10.13 \mathrm{GHz}, 0.42$ at $10.05 \mathrm{GHz}, 0.48$ at $9.96 \mathrm{GHz}, 0.52$ at $9.88 \mathrm{GHz}$, and 0.55 at $9.80 \mathrm{GHz}$ for pure polystyrene (PS), $5 \mathrm{wt} \% \mathrm{Co}-\mathrm{PS}, 10$ wt $\%$ Co-PS, 15 wt\% Co-PS, 20 wt $\%$ Co-PS, 25 wt\% Co-PS, 30 wt $\%$ Co-PS, respectively. The maximum of loss factors are shifted towards lower part of the X-band frequency with increasing the cobalt content, which is in compliance with the other reported experimental results. ${ }^{47,53,54}$ The increasing trend of loss factor with the addition of cobalt content may be explained from the fact that the low loss PS is converted into the lossy dielectric when it is mixed homogeneously with high concentration of cobalt fillers thus giving rise to high values of dielectric losses. The losses could also be attributed to the interfacial polarization developed at the metal-insulator interface (Maxwell-Wagner theory of interfacial polarization), where the electric charges are accumulated and increased by increasing the cobalt content. ${ }^{55}$ On the other hand, the existence of the maximum value is related to a polarization change with frequency. ${ }^{56}$ The shifting of the loss factor maximum with the loading of cobalt towards lower frequency region of the $\mathrm{X}$ band, is probably due to the increase of the PS/Co interface area and thus to space charge that separates on this interfaces and the PS molecular chains (dipole moment $\sim 0.26 \mathrm{D}$ due to the asymmetry at the phenyl side group) that are fixed on cobalt particles. ${ }^{47,54,57,58}$

The real part $\left(\mu^{\prime}\right)$ and the imaginary part $\left(\mu^{\prime \prime}\right)$ of the complex permeability are plotted in Fig. 10a and b as a function of frequency in the X-band. The values of real part and imaginary part of the complex permeability are, respectively, unity and zero in the whole frequency range of X-band for the nonmagnetic PS sample. The real part $\left(\mu^{\prime}\right)$ of the Co-PS composites decreases smoothly with frequency in the frequency range 8-10 $\mathrm{GHz}$, rises up to the maximum in the frequency range 10-10.2 $\mathrm{GHz}$, sharp decreases in the frequency range 9.96-10.47 GHz, raises up again and then decreases as increasing the cobalt content. The largest value of $\mu^{\prime}=1.56$ is obtained for $30 \mathrm{wt} \%$ Co-PS composite at the magnetic resonance frequency of 10.2
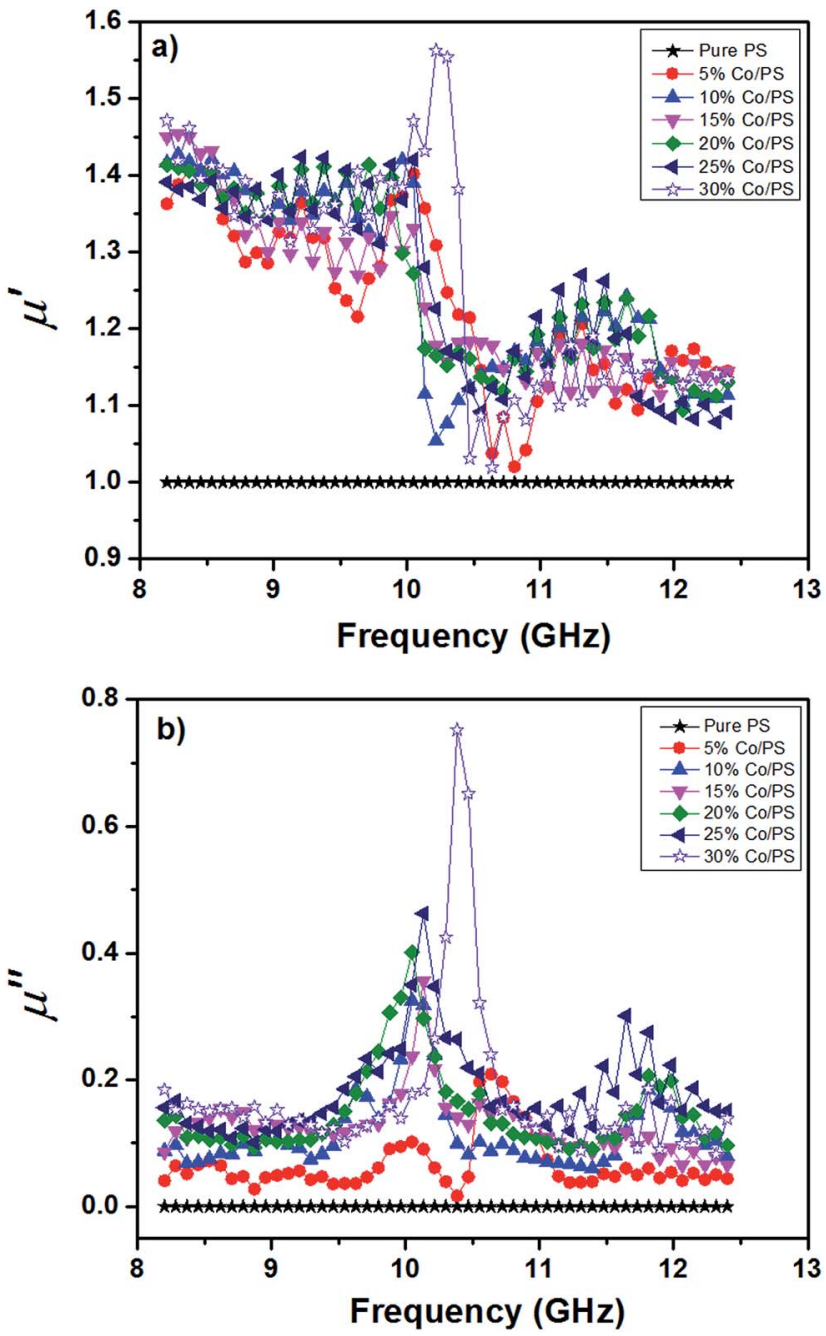

Fig. 10 The complex permeability of Co-PS composites (0-30 wt\% Co filler) in the $X$-band of microwave frequency, (a) real part of complex permeability, (b) imaginary part of complex permeability.

$\mathrm{GHz}$, while $\mu^{\prime}=1.40$ is obtained for $5 \mathrm{wt} \%$ Co-PS composite at the magnetic resonance frequency of $10.1 \mathrm{GHz}$. The aim of incorporating the cobalt into the PS matrix is to raise $\mu^{\prime}$ above unity in the whole frequency range of X-band. The lower values of permeability observed in these samples may be attributed to the presence of nonmagnetic PS polymer between the neighboring particles, which weakens the intergranular magnetic interaction. ${ }^{59}$

The imaginary part $\left(\mu^{\prime \prime}\right)$ of the complex permeability is slightly increasing with the cobalt content at $8.4 \mathrm{GHz}$. They exhibit sharp resonance peaks in the frequency range of 10-11 $\mathrm{GHz}$ with the values given by 0.21 at $10.64 \mathrm{GHz}, 0.33$ at 10.05 $\mathrm{GHz}, 0.36$ at $10.13 \mathrm{GHz}, 0.40$ at $10.05 \mathrm{GHz}, 0.46$ at $10.13 \mathrm{GHz}$, and 0.75 at $10.38 \mathrm{GHz}$ for 5, 10, 15, 20, 25, and $30 \mathrm{wt} \% \mathrm{Co}-\mathrm{PS}$ composites, respectively. Other small resonance peaks for the above mentioned samples are observed around 11.5-12 GHz frequency range. It is to be noted that the electromagnetic properties of ferromagnetic metal particles dispersed in the polymer matrix are controlled by eddy current effect, natural 
resonance and exchange resonance rather than magnetic hysteresis and domain wall resonance (for permeability), and space charge polarization. ${ }^{\mathbf{5 8 , 6 0 , 6 1}}$ In the cobalt particles, the natural resonance and exchange resonance coexist, which can also be attributed to the magnetic loss. ${ }^{52}$

The dielectric and magnetic loss tangents of Co-PS composites are shown in Fig. 11a and b, respectively. The dielectric loss tangent depends on the ratio of imaginary to real parts of the complex permittivity, while the ratio of the imaginary to real parts of the complex permeability determines the magnetic loss tangent. The maximum value of the dielectric loss tangent increases with the addition of the cobalt content, and shifts towards the lower part of the X-band of the microwave frequency. This is due to the combined effect of the real and imaginary parts of the complex permittivity.

The maximum magnetic loss tangent (Fig. 11b) of the Co-PS composites increases and shifts towards the lower part of the $\mathrm{X}$ band by increasing the cobalt content, which is due to the
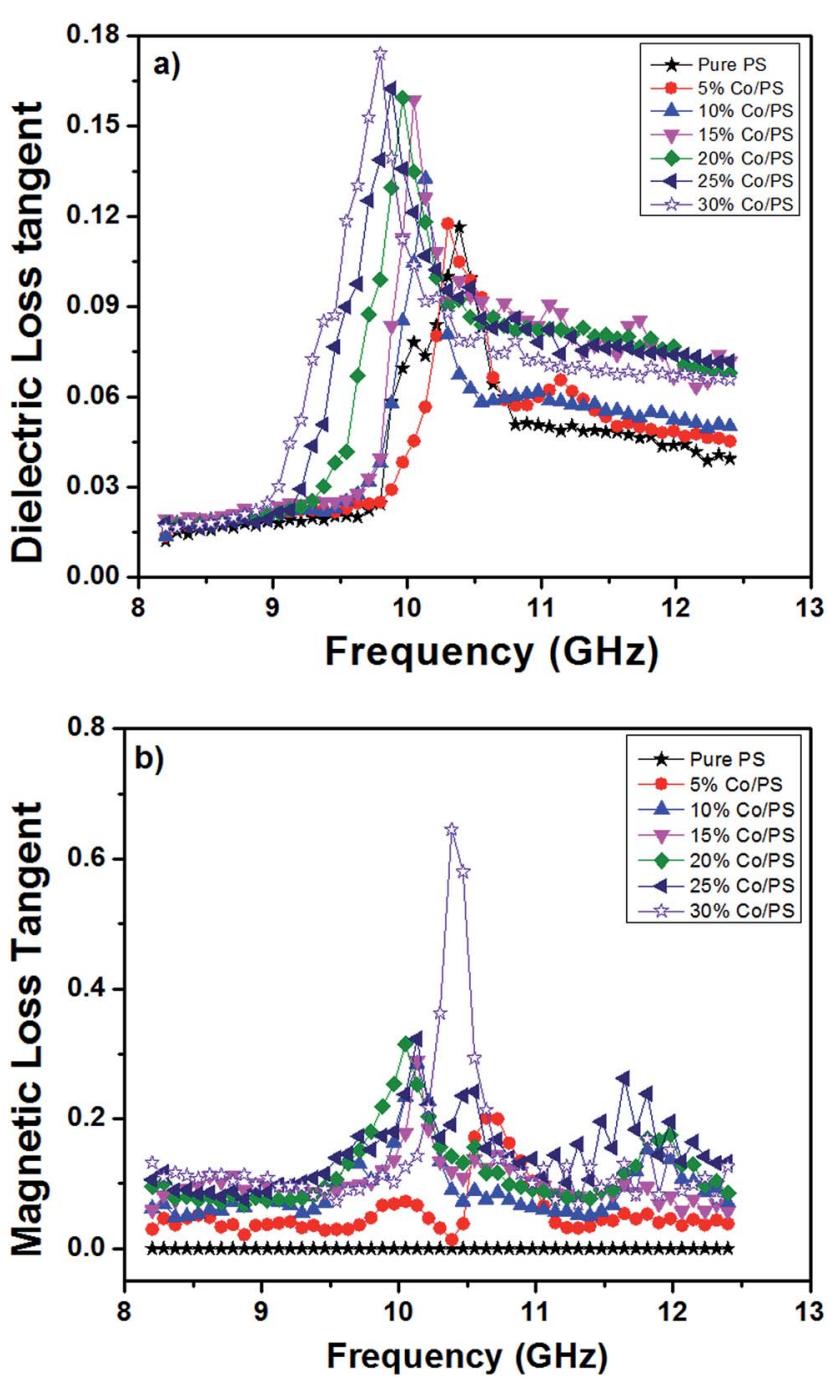

Fig. 11 The loss tangent of Co-PS composites (0-30 wt\% Co filler) in the $\mathrm{X}$-band of microwave frequency, (a) dielectric loss tangent, (b) magnetic loss tangent. combined effect of the real and imaginary parts of the complex permeability. Also, the addition of the cobalt particles into the PS matrix changes the magnetocrystalline anisotropy which results to generate the resonance peaks and therefore increases the magnetic loss tangent. ${ }^{62,63}$

The calculated reflection losses for Co-PS composites (thickness $\sim 5 \mathrm{~mm}$ ) with different cobalt contents using eqn (5) and (6) are shown in Fig. 12. The minimum reflection loss of $-1.98 \mathrm{~dB}$ at $10.38 \mathrm{GHz},-4.90 \mathrm{~dB}$ at $10.72 \mathrm{GHz},-8.31 \mathrm{~dB}$ at $10.13 \mathrm{GHz},-10.94 \mathrm{~dB}$ at $10.13 \mathrm{GHz},-14.69 \mathrm{~dB}$ at $10.05 \mathrm{GHz}$, $-15.15 \mathrm{~dB}$ at $10.47 \mathrm{GHz}$, and $-19.85 \mathrm{~dB}$ at $10.22 \mathrm{GHz}$ are obtained for polystyrene, $5 \mathrm{wt} \%$ Co-PS, $10 \mathrm{wt} \% \mathrm{Co}-\mathrm{PS}, 15 \mathrm{wt} \% \mathrm{Co}-$ PS, 20 wt $\%$ Co-PS, 25 wt $\%$ Co-PS, and 30 wt $\%$ Co-PS composite samples, respectively. The analysis shows that the minimum reflection loss (maximum absorption loss) in the composite samples is increased with the addition of cobalt filler in the polystyrene matrix. The microwave absorption mechanism can be explained by the fact that as the microwave radiation travels inside the material, it interacts with the filler particles successively and in the process loses energy as heat. High filler contents offer excess of filler particles in the composites, which increases the number of microwave-filler interactions, and consequently enhances the microwave absorbing capability of the composite.

Fig. 13a shows the variation of calculated reflection losses for $30 \mathrm{wt} \%$ Co-PS composite as a function of thickness in the Xband microwave frequency range. The results shown in Fig. 13a are analyzed by 3D color map surface plot which are represented in Fig. 13b, while the color fill patterns are shown in Fig. 13c. The variation of reflection loss minimum $\left(\mathrm{RL}_{\mathrm{min}}\right)$ with corresponding frequency and thickness for $30 \mathrm{wt} \% \mathrm{Co}-\mathrm{PS}$ composite is plotted in Fig. 13d. The variation in $\mathrm{RL}_{\min }$ and -10 $\mathrm{dB}$ bandwidth of this sample as a function of thickness is depicted in Fig. 13e, where no specific pattern is observed.

It can be analyzed from Fig. 13 that the $\mathrm{RL}_{\text {min }}$ shifts towards the lower part of the X-band microwave frequency with

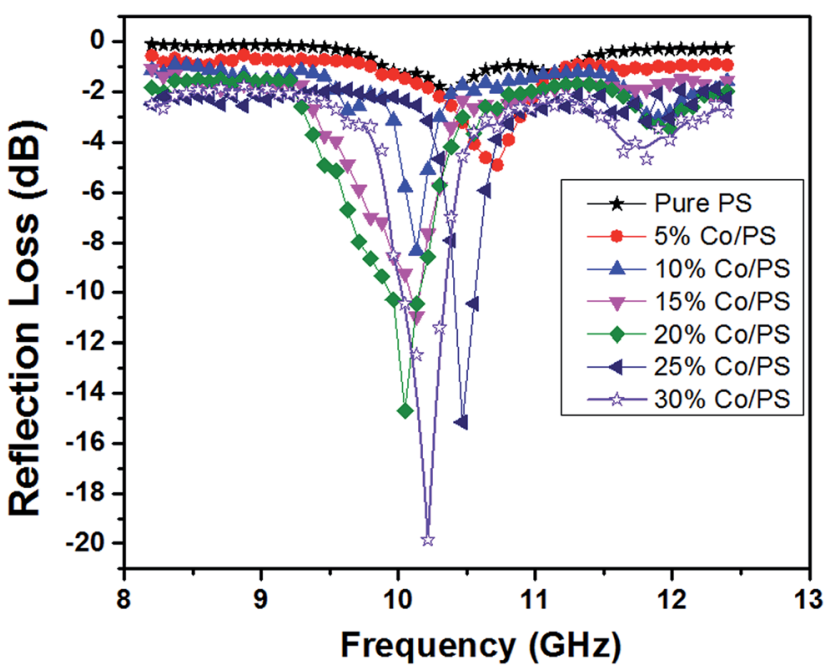

Fig. 12 The reflection loss of Co-PS composites (0-30 wt\% Co filler) in the X-band of microwave frequency. 

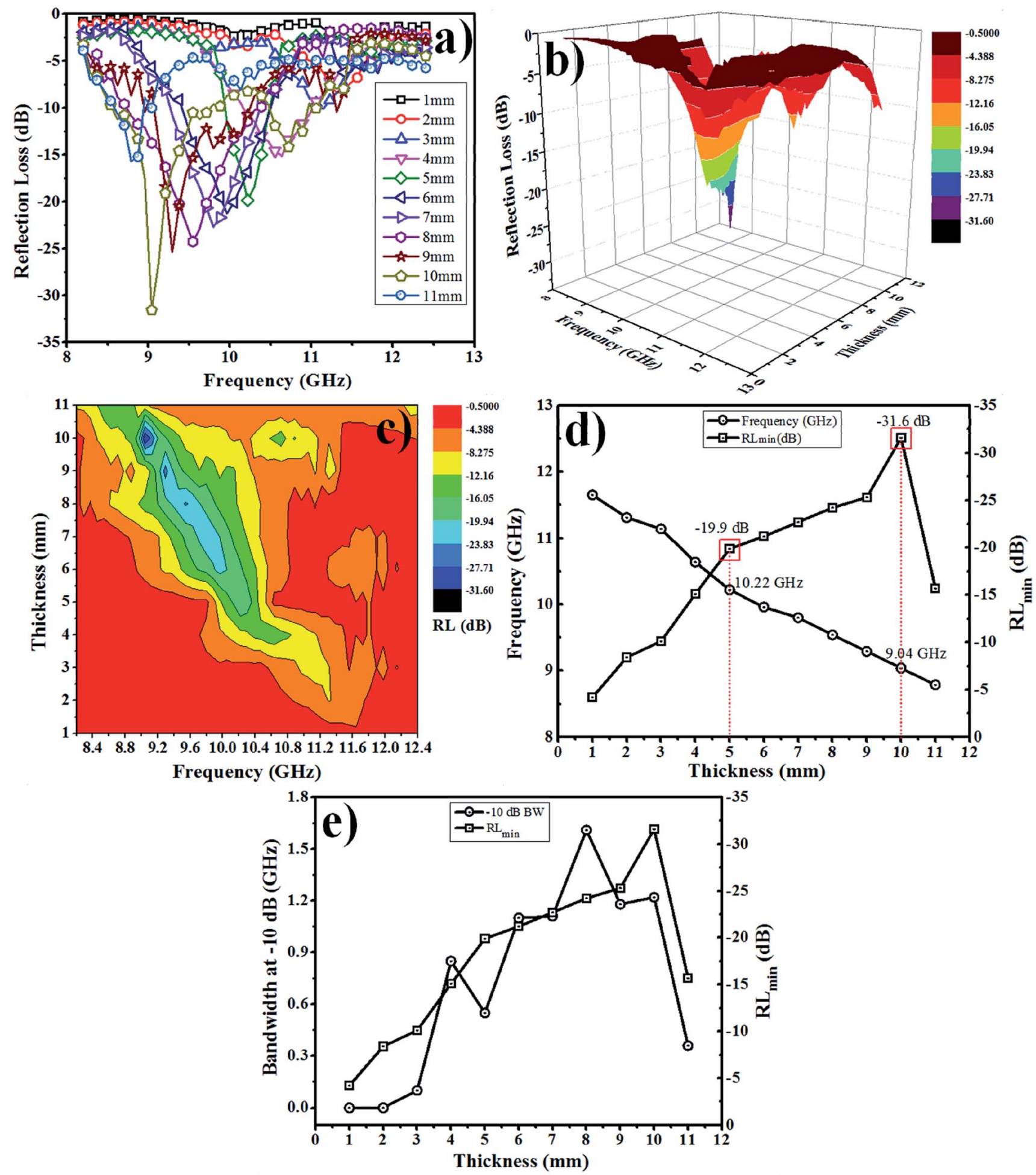

Fig. 13 (a) Frequency dependence of reflection loss for 30 wt\% Co-PS composite as a function of thickness, (b) 3D color map surface plot of RL, (c) color fill pattern, (d) summarized $\mathrm{RL}_{\min }$ with thickness and frequency, and (e) summarized $\mathrm{RL}_{\min }$ with thickness and at $-10 \mathrm{~dB} B W$.

increasing the thickness of the sample. This result is in accordance with the earlier reported results. ${ }^{64-67}$ The $\mathrm{RL}_{\min }$ gradually increases with increasing the thickness up to $10 \mathrm{~mm}$ and beyond $10 \mathrm{~mm}$, it starts decreasing. The minimum reflection loss of $-31.6 \mathrm{~dB}$ (maximum absorption of $99.93 \%$ ) in $30 \mathrm{wt} \%$
Co-PS composite can be achieved at matching frequency of 9.04 $\mathrm{GHz}$ for $10 \mathrm{~mm}$ matching thickness, which is the $59 \%$ improvement in $\mathrm{RL}_{\min }$ as compared to the result obtained in 5 $\mathrm{mm}$ sample thickness $\left(\mathrm{RL}_{\min } \sim-19.9 \mathrm{~dB}\right.$ implies $98.96 \%$ absorption loss). 
However, increasing the thickness of the microwave absorber will surely increase the weight of the microwave absorber, and thus restrict its applications. The optimum thickness of the $30 \mathrm{wt} \%$ Co-PS composite to which a significant reflection loss is achieved, ranges $\mathbf{5 - 1 0 ~} \mathrm{mm}$ with corresponding frequency interval of 9.04-10.22 GHz. From the point of view of microwave absorber, the Co-PS composites with higher filler content can be used as quite efficient microwave absorbers in the X-band of microwave frequency. ${ }^{68}$

\section{Conclusion}

The cobalt-polystyrene composites with different cobalt content have been synthesized via automated injection molding method. The XRD has been performed to identify the existence of cobalt particles in the composite samples. The interaction of cobalt particles with polymer chain is also studied from XRD results. The morphological study of the composite samples has been done with the help of SEM. The dispersion of cobalt nanoparticles in the polystyrene matrix has been demonstrated from the cross sectional SEM images of the composite samples. The surface hardness of the composites (Shore D) has been measured, which is found to increase with higher cobalt contents. It has been observed that the tensile and flexural strengths of the molded composites increase with the increase in cobalt content. This enhancement in mechanical properties can be attributed to the reinforcement effect of cobalt fillers in the polystyrene matrix. In order to study the thermal stability of the cobalt-polystyrene composite, thermo gravimetric analysis (TGA) has been carried out. The analysis of TGA/DTA results shows that the thermal stability of the synthesized Co-PS composites increases on increasing the cobalt contents. The complex permittivity and permeability of the Co-PS composite samples have been measured using the vector network analyzer in the X-band (8.4-12.4 GHz) of microwave frequency. The real part of the complex permittivity is almost constant in the whole $\mathrm{X}$-band of microwave frequency for a given cobalt concentration, while it increases with the significant increase of cobalt content in the polystyrene matrix. The imaginary part of the complex permittivity (loss factor) increases with the addition of cobalt content which can be attributed to the conversion of low loss PS into the lossy dielectric due to presence of high concentration of cobalt conducting fillers. In all the Co-PS composite samples, the real part of the complex permeability has been found to be greater than unity in the whole X-band, while the imaginary part (loss factor) is slightly increased with the addition of cobalt and shows the resonance peaks. The increased magnetic loss in the composite samples is attributed to the ferromagnetic cobalt particles where the natural resonance and exchange resonance coexist. The microwave absorbing capability of the Co-PS composite samples has been found to increase with the addition of higher filler content. For $30 \mathrm{wt} \%$ Co-PS composite, the reflection loss at different sample thicknesses has been calculated. The minimum reflection loss of $-31.6 \mathrm{~dB}$ (maximum absorption of $99.93 \%$ ) has been achieved for $10 \mathrm{~mm}$ at $9.04 \mathrm{GHz}$, while for $5 \mathrm{~mm}$ thick sample this value is $-19.9 \mathrm{~dB}$ (maximum absorption $\sim 98.96 \%$ ) at 10.22
GHz. Hence, it can be concluded that the Co-PS composite with higher filler content appears to be a promising candidate for microwave absorber applications in the X-band of microwave frequency. The addition of $30 \mathrm{wt} \%$ Co filler to the PS matrix does not significantly increase the weight of the resultant composite thus making this absorber quite useful for RADAR, high frequency devices, aerospace and stealth applications.

\section{Acknowledgements}

The authors acknowledge Prof. Kamal K. Kar and H. B. Baskey for TGA/DTA and VNA measurements, respectively.

\section{References}

1 A. W. Radasky, E. C. Baum and M. W. Wik, IEEE Trans. Electromagn. Compat., 2004, 46, 314.

2 G. C. Messenger and M. S. Ash, The Effect of Radiation on Electronic Systems, Van Nostrand Co. Inc., New York, USA, 1986.

3 A. F. Molisch, Wireless Communication, John Wiley \& Sons Ltd., West Sussex, UK, 2nd edn, 2012.

4 H. K. Miller, Mater. Eval., 1997, 55, 994.

5 Z. Sienkiewicz, J. Power Eng., 1998, 12, 131.

6 X. Liu, S. W. Or, C. M. Leung and S. L. Ho, J. Appl. Phys., 2014, 115, 17 A507.

7 V. A. Labunov, A. L. Danilyuk, A. L. Prudnikava, I. Komissarov, B. G. Shulitski, C. Speisser, F. Antoni, F. L. Normand and S. L. Prischepa, J. Appl. Phys., 2012, 112, 024302.

8 R. K. Srivastava, T. N. Narayanan, A. P. R. Mary, M. R. Anantharaman, A. Srivastava, R. Vajtai and P. M. Ajayan, Appl. Phys. Lett., 2011, 99, 113116.

9 C. J. V. Klemperer and D. Maharaj, Composite Structures, 2009, 91, 467.

10 N. C. Das, D. Khastgir, T. K. Chaki and A. Chakraborty, Composites, Part A, 2000, 31, 1069.

11 W. William, Absorption of Electromagnetic Radiation, Access Science, McGraw-Hill Education, New York, USA, 2014.

12 X. C. Zhao, Z. Zhang, L. Wang, K. Xi, Q. Cao, D. Wang, Y. Yang and Y. Du, Sci. Rep., 2013, 3, 3421.

13 J. Smit and H. P. J. Wijn, Ferrites, Philips Technical Library, Eindhoven, 1959.

14 X. G. Liu, D. Y. Geng, H. Meng, P. J. Shang and Z. D. Zhang, Appl. Phys. Lett., 2008, 92, 173117.

15 L. Yan, J. Wang, X. Han, Y. Ren, Q. Liu and F. Li, Nanotechnology, 2010, 21, 095708.

16 Z. D. Zhang, Z. C. Shi, R. H. Fan, M. Gao, J. Y Guo, X. G. Qi and K. N. Sun, Mater. Chem. Phys., 2011, 130, 615.

17 S. S. Kim, S. T. Kim, Y. C. Yoon and K. S. Lee, J. Appl. Phys., 2005, 97, 10F905.

18 M. Matsumoto and Y. Miyata, J. Appl. Phys., 2002, 91, 9635. 19 O. Akman, H. Kavas, A. Baykal, M. S. Toprak, A. Coruh and B. Aktas, J. Magn. Magn. Mater., 2013, 327, 151.

20 S. S. Kim, S. B. Jo, K. I. Gueon, K. K. Choi, J. M. Kim and K. S. Chum, IEEE Trans. Magn., 1991, 27, 5462. 
21 S. M. Abbas, R. Chatterjee, A. K. Dixit, A. V. R. Kumar and T. C. Goel, J. Appl. Phys., 2007, 101, 074105.

22 S. M. Abbas, M. Chandra, A. Verma, R. Chatterjee and T. C. Goel, Composites, Part A, 2006, 37, 2148.

23 A. N. Yusoff, M. H. Abdullah, S. H. Ahmad, S. F. Jusoh, A. A. Mansor and S. A. A. Hamid, J. Appl. Phys., 2002, 92, 876. 24 S. M. Abbas, A. K. Dixit, R. Chatterjee and T. C. Goel, J. Magn. Magn. Mater., 2007, 309, 20.

25 H. Wang, N. Ma, Z. Yan, L. Deng, J. He, Y. Hou, Y. Jiang and G. Yu, Nanoscale, 2015, 7, 7189.

26 A. Z. Michael, L. V. Michael, S. R. Judy, S. Martin and G. S. P. Timothy, Chem. Mater., 2007, 19, 6597.

27 V. F. Puntes, P. Gorostiza, D. M. Aruguete, N. G. Bastus and A. P. Alivisatos, Nat. Mater., 2004, 3, 263.

28 J. R. Wunsch, Polystyrene - Synthesis, Production and Applications, iSmithers Rapra Publishing, Shawbury, United Kingdom, 2000.

29 A. M. Nicolson and G. F. Ross, IEEE Trans. Instrum. Meas., 1970, 19, 377.

30 J. B. Javis, E. J. Vanzura and W. A. Kissick, IEEE Trans. Microwave Theory Tech., 1990, 38, 1096.

31 T. Zhao, C. Hou, H. Zhang, R. Zhu, S. She, J. Wang, T. Li, Z. Liu and B. Wei, Sci. Rep., 2014, 4, 5619.

32 T. Zou, H. Li, N. Zhao and C. Shi, J. Alloys Compd., 2010, 496, L22-L24.

33 A. W. Hull, Phys. Rev., 1921, 17, 571-588.

34 Z. Wang and G. L. Zhao, Open J. Compos. Mater., 2013, 3, 17. 35 A. S. Kurlova and A. A. Rempel, Inorg. Mater., 2013, 49, 889.

36 B. Paul, A. Verma, A. C. Bidaye, R. C. Hubli and A. K. Suri, J. Mater. Metall. Eng., 2012, 1, 23.

37 M. Suzuki and C. A. Wilkie, Polym. Degrad. Stab., 1995, 47, 217.

38 R. Ding, Y. Hu, Z. Gui, R. Zong, Z. Chen and W. Fan, Polym. Degrad. Stab., 2003, 81, 473.

39 Azizurrahaman, A. K. Jha and M. J. Akhtar, Adv. Powder Technol., 2015, 26, 1281.

40 J. Kuljanin, M. M. Cincovic, Z. Stojanovic, A. Krkljes, N. D. Abazovic and M. I. Comor, Polym. Degrad. Stab., 2009, 94, 891.

41 S. R. Dhakate, R. B. Mathur, B. K. Kakati and T. L. Dhami, Int. J. Hydrogen Energy, 2007, 32, 4537.

42 M. A. Alam, S. Arif and M. Shariq, Int. J. Innov. Res. Adv. Eng., $2015,2,122$.

43 H. Huang and J. T. Zhang, J. Appl. Polym. Sci., 2009, 111, 2806.

44 T. P. Selvin, J. Kuruvilla and T. Sabu, Mater. Lett., 2004, 58, 281.
45 D. Panaitescu and P. V. Notingher, Plastic Materials, 2002, 39, 56.

46 H. Zois, L. Apekis and Y. P. Mamunya, J. Appl. Polym. Sci., 2003, 88, 3013.

47 J. Yacubowicz and M. Narkis, Polym. Eng. Sci., 1990, 30, 469. 48 H. S. Gokturk, T. J. Fiske and D. H. Kalyon, IEEE Trans. Magn., 1993, 29, 4170.

49 G. M. Tsangaris, G. C. Psarras and N. kouloumbi, J. Mater. Sci., 1998, 33, 2027.

50 T. Liu, J. Fothergill, S. Dodd and U. Nilsson, J. Phys.: Conf. Ser., 2009, 183, 1.

51 . B. David Cruickshank, Microwave Materials for Wireless Applications, Norwood, MA, 2011, p. 50.

52 H. Wang, N. Ma, Z. Yan, L. Deng, J. He, Y. Hou, Y. Jiang and G. Yu, Nanoscale, 2015, 7, 7189.

53 P. Morshuis, Interfaces to be Avoided or to be Treasured 2013: 2013 IEEE International Conference on Solid Dielectrics, Bologna, Italy, 30 June-4 July 2013, pp. 1-9.

54 D. Panaitescu, Z. Vuluga, P. V. Notingher and C. Nicolae, Polym. Eng. Sci., 2013, 53, 2081.

55 T. Hanai and K. Sekine, Colloid Polym. Sci., 1986, 264, 888.

56 J. Yacubowicz, M. Narkis and L. Benguigui, Polym. Eng. Sci., 1988, 28, 1581.

57 A. J. Bur, Polymer, 1985, 26, 963.

58 S. S. Kim, S. T. Kim, Y. C. Yoon and K. S. Lee, J. Appl. Phys., 2005, 97, 10F905.

59 R. B. Yang, W. F. Liang, C. W. Lou and J. H. Lin, J. Appl. Phys., 2012, 111, 07A338.

60 X. Fan, J. Guan, W. Wang and G. Tong, J. Phys. D: Appl. Phys., 2009, 42, 075006.

61 H. Wang, H. H. Guo, Y. Y. Dai, D. Y. Geng, Z. Han, D. Li, T. Yang, S. Ma, W. Liu and Z. D. Zhang, Appl. Phys. Lett., 2012, 101, 083116.

62 X. L. Dong, X. F. Zhang, H. Huang and F. Zuo, Appl. Phys. Lett., 2008, 92, 013127.

63 P. Toneguzzo, G. Viau, O. Acher, F. Guillet, E. Bruneton, F. F. Vincent and F. Fievet, J. Mater. Sci., 2000, 35, 3767.

64 X. G. Chen, J. P. Cheng, S. S. Lv, P. P. Zhang, S. T. Liu and Y. Ye, Compos. Sci. Technol., 2012, 72, 908.

65 X. G. Chen, S. S. Lv, P. P. Zhang, J. P. Cheng, S. T. Liu and Y. Ye, J. Magn. Magn. Mater., 2012, 324, 1745.

66 S. T. Liu, K. K. Yan, Y. H. Zhang, S. D. Jin, Y. Ye and X. G. Chen, J. Magn. Magn. Mater., 2015, 394, 266.

67 A. B. Zhang, S. T. Liu, K. K. Yan, Y. Ye and X. G. Chen, RSC Adv., 2014, 4, 13565.

68 X. F. Zhang, X. L. Dong, H. Huang, B. Lv, J. P. Lei and C. J. Choi, J. Phys. D: Appl. Phys., 2007, 40, 5383. 